Check for updates

Cite this: RSC Adv., 2018, 8, 21316

Received 3rd May 2018

Accepted 28th May 2018

DOI: $10.1039 / \mathrm{c} 8 \mathrm{ra03795g}$

rsc.li/rsc-advances

\section{Seedless preparation of Au nanorods by hydroquinone assistant and red blood cell membrane camouflage $\dagger$}

\author{
Jing Li, ${ }^{a}{ }^{a}$ Wenjing Wang, ${ }^{b}$ Xue Zhang, ${ }^{c}$ Hua Yao, ${ }^{a}$ Zhenhong Wei, ${ }^{a}$ Xiuying $\mathrm{Li}{ }^{\mathrm{a}}$ \\ Xupeng Mu, ${ }^{a}$ Jinlan Jiang*a and Hao Zhang (iD *b
}

\begin{abstract}
Au nanorods (AuNRs) have attracted extensive attention in diagnosis and therapy, because of their excellent photothermal effects. Although many of attempts have been employed to prepare AuNRs with a good-size monodispersity, facile and feasible preparation methods are still welcomed in consideration of theranostics-related photothermal applications. In this work, AuNRs are prepared through a seedless method using hydroquinone as the reductant. The longitudinal located surface plasmon resonance peak of the as-prepared AuNRs can be tuned from 650 to $840 \mathrm{~nm}$ and the AuNRs indicate a good photothermal conversion efficiency. To lower the toxicity, natural red blood cell membranes are employed to coat the AuNRs. In the primary experiment in vitro, red blood cell membrane-coated AuNRs exhibit good biocompatibility and photothermal treatment effect.
\end{abstract}

\section{Introduction}

Photothermal therapy, which can convert the incident nearinfrared (NIR) irradiation to thermal energy and kill the cancer cells in a noninvasive way, has attracted wide attention in tumor treatments..$^{1-4}$ The key factors influencing photothermal therapy efficacy mainly have two aspects, photothermal transduction agents with a high photothermal transduction efficiency and adequate accumulation within the tumor in vivo. NIR photothermal agents currently under active investigations include carbon-based $\mathrm{NPs},{ }^{5-7} \mathrm{Fe}_{3} \mathrm{O}_{4},{ }^{8-10}$ and $\mathrm{Au}$ nanostructures. ${ }^{11-13}$ Owing to the facile preparation, tunable longitudinal located surface plasmon resonance (LSPR) peaks in the NIR region and convenient surface modification, Au nanoparticles with a variety of morphology, such as nanocages, nanoshells, nanostars, and nanorods, have been actively studied. ${ }^{\mathbf{1 4 - 1 7}}$ Among them, Au nanorods (AuNRs) have attracted considerable attention due to their unique optical properties, which exhibit two absorption peaks with one at around $520 \mathrm{~nm}$ and the other around the NIR regions. ${ }^{18}$ So the AuNRs are very

${ }^{a}$ The Scientific Research Center, China-Japan Union Hospital, Jilin University, 126 Xiantai Street, Changchun 130033, P. R. China.E-mail: jiangjl2003@hotmail.com ${ }^{b}$ State Key Laboratory of Supramolecular Structure and Materials, College of Chemistry, Jilin University, Changchun 130012, P. R. China.E-mail: hao_zhang@ jlu.edu.cn

${ }^{c}$ College of Resources and Environment, Jilin Agricultural University, Changchun 130118, China

$\dagger$ Electronic supplementary information (ESI) available: Additional characterizations using hydroquinone as reductant in producing AuNRs, the stability of RBCM-AuNRs, and the calculation of $\eta$ of AuNRs. See DOI: 10.1039/c8ra03795g suitable for photothermal therapy by converting the $808 \mathrm{~nm}$ incident laser with a high transduction efficiency. ${ }^{19-21}$ Seedmediated growth is the most widely used method in the preparation of AuNRs, which was initially developed by Murphy and co-workers in 2001. ${ }^{22}$ They introduced cetyl trimethyl ammonium bromide (CTAB) as the template to direct the growth of the AuNRs along the long axis under the reducing ascorbic acid. Then a variety of protocols derived from this method were widely attempted to prepare monodisperse AuNRs with tunable length. ${ }^{23-25} \mathrm{Zhu}$ et al. utilized dopamine as the reductant to prepare AuNRs of high quality, in which the LSPR peaks can be tuned from 680 to $1030 \mathrm{~nm} .{ }^{26}$ Murray and co-workers reported a protocol to obtain monodisperse AuNRs by introducing salicylic acid as an aromatic additive. ${ }^{27}$ Aromatic compounds can modify the micellization behavior of CTAB, thus lowering the amount of CTAB compared with traditional protocols. Their systematic experiments proved that the introduction of aromatic compounds in the preparation of AuNRs was of benefit for producing high quality AuNRs.

Seed-mediated methods have been widely used to prepare AuNRs for many years. However, the reliability and reproducibility of the seed-mediated methods are limited by the quality of the Au seeds. ${ }^{28}$ So, recently, a seedless growth protocol was developed that does not need to prepare the $\mathrm{Au}$ seeds in advance to prepare the AuNRs. ${ }^{29-31}$ So this protocol can save the error-prone step, and get a higher yield. ${ }^{31}$ Wang et al. chose resveratrol as the reductant to prepare the AuNRs a by seedless method. The LSPR could be adjusted from 570 to $950 \mathrm{~nm}$ by regulating the reaction agents. However, the yield of AuNRs was only $77 \%$, which was attributed to a low solubility and weaker reducibility of resveratrol compared with other reductants. ${ }^{29}$ So 
choosing an appropriate reductant is vital for the preparation of high quality and yield AuNRs. Hydroquinone (HQ) is a mild reductant widely used in preparing anisotropic nanostructures, such as branched nanostructures and nanorods. ${ }^{32,33}$ Owing to the mild reducibility, HQ can support AuNR growth along the long axis instead of secondary nucleation. ${ }^{34,35}$ And, benefiting from the aromatic compounds of the HQ, it can interfere with the micellization behavior of CTAB, and thus favor the gain of monodisperse AuNRs. ${ }^{36}$ So $\mathrm{HQ}$ is a potential reductant to prepare the AuNRs by a seedless method.

AuNRs with LSPR peaks around $800 \mathrm{~nm}$ can have a high photothermal transduction efficiency, and are considered as promising photothermal agents. ${ }^{37}$ However, further theranostic applications of AuNRs have two disadvantages: cytotoxicity brought about by $\mathrm{CTAB},{ }^{38}$ and a quick clearance by immune cells. ${ }^{39}$ Many efforts have been tried to reduce the cytotoxicity and prolong the circulation time in vivo by modifying biocompatible materials. Chen and co-workers utilized mesoporous $\mathrm{SiO}_{2}$ as a biocompatible shell to coat on the surface of AuNRs, and further delivered Dox in the mesoporous $\mathrm{SiO}_{2}$ to realize chemo-photothermal therapy. ${ }^{\mathbf{4 0}}$ Zhang and co-workers employed polydopamine as the coating material to reduce the nanotoxicity of AuNRs, and further loaded $\mathrm{Cu}^{2+}$ in the polydopamine shell to endow a magnetic resonance imaging function. They designed and fabricated a multimodal theranostic nanodevice based on the AuNRs. ${ }^{39}$ SH-PEG and derivatives are also usually used to exchange the CTAB from the AuNRs to reduce the cytotoxicity and the nonspecific adsorption by proteins. However, accumulation studies have reported that PEGylated nanoparticles induced the production of anti-PEG immunoglobulin M (IGM) antibodies, which led to a rapid clearance of subsequently added nanoparticles. ${ }^{\mathbf{4 1 , 4 2}}$ So the shorter half-life of PEG-AuNRs will limit the utility of PEGylation nanoparticles in vivo. Very recently, natural cellular membranes as a biomimetic nanocoating have attracted a wide research interest to improve the biocompatibility of the nanocomposites and reduce blood clearance. ${ }^{43-51}$ With the "do not eat me" marker CD47 and other membrane proteins on the red blood cell (RBC) membrane surface, the cell-mimicking nanomaterials can effectively reduce nonspecific macrophage uptake and prolong blood retention time. ${ }^{52,53}$ Zhang's group pioneered the RBC membrane-camouflaged nanoparticles to drug delivery. ${ }^{54}$ They gained the RBC membranes by a hypotonic treatment to burst the RBC cells, followed by extrusion through porous membranes to create RBC membrane vesicles. And the RBC membrane vesicles with PLGA nanoparticles were extruded through porous membranes to fabricate the RBC-membranecamouflaged polymeric nanoparticles as a biomimetic delivery platform. Liu et al. systematically compared the half-life of $\mathrm{Fe}_{3} \mathrm{O}_{4}$ nanoparticles fabricated with PEG and natural RBC membranes. ${ }^{41}$ In vitro macrophage uptake and in vivo pharmacokinetic studies had demonstrated that RBC membranes were a superior alternative to PEG for prolonging the systematic circulation time of nanoparticles. The unique properties reveal that the cell membrane-camouflaged nanoparticles have a huge potential to fabricate smart delivery systems.
In this work, HQ was employed as the reductant for the seedless preparation of monodisperse Au NRs. By regulating the dosage of the reaction reagents, the LSPR peaks of the asprepared AuNRs could be adjusted to the NIR region, generating a high photothermal conversion efficiency. Natural RBC membranes were introduced as a biocompatible coating for the AuNRs (RBCM-AuNRs) to reduce the cell toxicity, which benefited the theranostics applications of AuNRs. In vitro experiments, the cell viability incubated with RBCM-AuNRs was dramatically enhanced compared with that of uncoated AuNRs. And the photothermal killing effect on the cancer cells with 40 $\mu \mathrm{g} \mathrm{mL} \mathrm{L}^{-1}$ RBCM-AuNRs can reach $10 \%$ of cell viability in under 8 min with a $1.5 \mathrm{~W} \mathrm{~cm}^{-2} 808 \mathrm{~nm}$ laser irradiation. This method provides a new strategy for AuNR-biocompatible modification, which exhibits a significant advantage in prolonging the circulation time for in vivo therapy.

\section{Experimental}

\subsection{Materials}

$\mathrm{HAuCl}_{4} \cdot 4 \mathrm{H}_{2} \mathrm{O}(48 \%), \mathrm{AgNO}_{3}$ (99\%), hydroquinone (98\%), and $\mathrm{NaBH}_{4}$ (99\%) were obtained from Sinopharm Chemicals Reagent Co. Ltd. CTAB (99\%) and sodium dodecyl sulfate (SDS, 99\%) were purchased from Sigma-Aldrich. The Dulbecco's modified Eagle's medium with high glucose (H-DMEM), fetal bovine serum (FBS), penicillin-streptomycin solution and trypsin-EDTA solution were obtained from Gibco. The Cell Count Kit-8 (CCK-8) used for cell viability was purchased from Dojindo Laboratories. CD47 antibody was purchased from Proteintech. The Annexin V-FITC/PI kit used for flow cytometry was purchased from Sungene Biotech Co. Propidium iodide (PI) used for staining cells was the product of Key Gen BioTech. All the other chemicals were analytical grade and used as received.

\subsection{Preparation of AuNRs}

AuNRs were prepared by a seedless method with HQ as the reductant. $50 \mu \mathrm{L}$ of $100 \mathrm{mM} \mathrm{HAuCl}{ }_{4}$ was added into $10 \mathrm{~mL}$ of $0.05 \mathrm{mM}$ CTAB solution, followed by adding $100 \mu \mathrm{L}$ of $0.1 \mathrm{M}$ $\mathrm{AgNO}_{3}$ solution. Subsequently, $1 \mathrm{~mL}$ of $30 \mathrm{mM}$ HQ was added into the growth solution, and the color of the growth solution turned to colorless within 1 min under hand-stirring. Finally, 15 $\mu \mathrm{L}$ of ice-cold $10 \mathrm{mM} \mathrm{NaBH}_{4}$ was added into the growth solution to trigger the reaction. The growth solution was incubated in a $30{ }^{\circ} \mathrm{C}$ water bath for $3 \mathrm{~h}$ to obtain the AuNRs.

\subsection{Photothermal conversion experiments}

A $3 \mathrm{~mL}$ AuNR solution with a specific concentration was placed in a $1 \times 1 \times 4 \mathrm{~cm}$ quartz cuvette cell. An $808 \mathrm{~nm}$ diode laser was used to irradiate the solution under a specific power density. The temperature of the solution was tracked by a digital thermometer.

\subsection{RBC membrane derivation}

RBC membranes were prepared as previously reported by Zhang et al. with modifications. ${ }^{54}$ Briefly, the whole blood was collected from balb/c mice by extracting the eyeball blood with a heparin- 
treated sterile centrifuge tube and then centrifuged at $800 \mathrm{~g}$ for $5 \mathrm{~min}$ at $4{ }^{\circ} \mathrm{C}$. The resulting RBCs were washed with $1 \times$ PBS twice to remove the plasma and the buffy coat. Then the RBCs were dispersed in $0.2 \times$ PBS for $1 \mathrm{~h}$ at $4{ }^{\circ} \mathrm{C}$ to rupture the RBCs and subsequently centrifuged at $15000 \mathrm{~g}$ for $8 \mathrm{~min}$ to remove the hemoglobin. The collected light-pink pellet, which contained the RBC membranes, was washed with $1 \times$ PBS twice, and the resulting RBC membranes was suspended and stored in $4{ }^{\circ} \mathrm{C}$.

\subsection{Preparation of RBCM-AuNRs}

The as-prepared AuNRs were centrifuged at $8000 \mathrm{~g}$ for $10 \mathrm{~min}$ twice to remove the excess CTAB and re-dispersed in deionized water. The solution was then mixed with a certain amount of $4 \mathrm{mM}$ SDS solution to perform a surface ligand exchange. After stirring overnight, CTAB and excess SDS were removed by centrifugation, and the obtained AuNRs stabilized by SDS (SDSAuNRs) were dispersed in PBS. Finally, $1 \mathrm{~mL}$ of SDS-AuNRs with an $\mathrm{Au}$ content of $100 \mu \mathrm{g} \mathrm{m \textrm {m } ^ { - 1 }}$ was mixed with RBC membranes derived from $1 \mathrm{~mL}$ of whole blood. The mixture was subsequently extruded through a $200 \mathrm{~nm}$ polycarbonate porous membrane 10 times. RBCM-AuNRs were obtained by centrifugation at $8000 \mathrm{~g}$ to remove excess RBC membranes. The AuNRs coated with SDS and RBC membranes were monitored by measuring the zeta-potentials to show the change of surface charge.

\subsection{Cytotoxicity assay}

Human lung carcinoma (A549) cells were selected as representative cancerous cells. A549 cells at an initial density of $1 \times 10^{4}$ cells per well were incubated in 96-well plates for $24 \mathrm{~h}$, followed by the addition of different concentrations of CTAB-AuNRs, SDS-AuNRs, and RBCM-AuNRs in the culture medium at $37{ }^{\circ} \mathrm{C}$ in a humidified $5 \% \mathrm{CO}_{2}$ atmosphere for $24 \mathrm{~h}$. A CCK-8 assay was used to analyze the cell viability. The optical density was measured at $450 \mathrm{~nm}$ for the CCK-8 assay. These three AuNRs at each concentration were assayed in five wells in parallel.

\subsection{Annexin $\mathrm{V}$ apoptosis assay}

The A549 cells at an initial density of $5 \times 10^{5}$ cells per well were seeded in 6-well culture plates and incubated for $24 \mathrm{~h}$ followed by adding $80 \mu \mathrm{g} \mathrm{mL}^{-1} \mathrm{RBCM}$-AuNRs for $24 \mathrm{~h}$ of incubation. The control group only needed the culture medium to be refreshed. Then the cells were harvested and washed twice with cooled PBS. The cells were re-dispersed in $100 \mu \mathrm{L}$ of binding buffer, followed by the addition of $5 \mu \mathrm{L}$ of Annexin V-FITC and $5 \mu \mathrm{L}$ of PI staining solution. The mixture was placed at room temperature for $15 \mathrm{~min}$ avoiding light. Finally, $400 \mu \mathrm{L}$ of binding buffer was added, and the samples were detected using a Beckman Coulter FC 500 flow cytometer.

\subsection{Cell cycle analysis}

The A549 cells at an initial density of $5 \times 10^{5}$ cells per well were seeded in 6-well culture plates and incubated for $24 \mathrm{~h}$, followed by incubating with $80 \mu \mathrm{g} \mathrm{mL}^{-1}$ RBCM-AuNRs for $24 \mathrm{~h}$. The control group only needed the culture medium to be refresh. The cells were harvested and washed with cooled PBS and then were fixed in $70 \%$ ice-chilled alcohol at $4{ }^{\circ} \mathrm{C}$ for $24 \mathrm{~h}$. The fixed cells were washed twice with PBS and re-dispersed in $0.5 \mathrm{~mL}$ of staining solution containing $50 \mu \mathrm{g} \mathrm{mL}^{-1} \mathrm{PI}, 100 \mu \mathrm{g} \mathrm{mL}^{-1}$ RNase $\mathrm{A}$, and $0.2 \%$ Triton $\mathrm{X}-100$, and then incubated for $30 \mathrm{~min}$ avoiding light. The cells were then analyzed using a Beckman Coulter FC 500 flow cytometer.

\subsection{Photothermal effect and apoptotic staining}

To quantitatively evaluate the photothermal effect in vitro, the A549 cells were seeded in 96-well plates at an initial density of 1 $\times 10^{4}$ cells per well in $0.1 \mathrm{~mL}$ of culture medium and incubated at $37^{\circ} \mathrm{C}$ overnight. After the cellular supernatant was discarded, the cells were incubated with $0.1 \mathrm{~mL}$ of $40 \mu \mathrm{g} \mathrm{mL}{ }^{-1}$ of RBCMAuNRs at $37{ }^{\circ} \mathrm{C}$ for $4 \mathrm{~h}$. The samples were irradiated under the $808 \mathrm{~nm}$ laser with different laser power densities for $8 \mathrm{~min}$. The plates were analyzed for cell viability by CCK-8 assay. Each sample was assayed in five wells in parallel. For the apoptotic staining, the A549 cells incubated with $40 \mu \mathrm{g} \mathrm{mL}{ }^{-1}$ RBCMAuNRs were exposed to the $808 \mathrm{~nm}$ laser with different power densities for $8 \mathrm{~min}$. PI was used to stain the apoptotic cells. Similarly, The A549 cells incubated with RBCM-AuNRs with different concentrations were exposed to $1.5 \mathrm{~W} \mathrm{~cm}^{-2} 808 \mathrm{~nm}$ laser for $8 \mathrm{~min}$. The cell viability was measured by CCK- 8 assay. Each concentration was assayed in five wells and repeated three times.

\subsection{Characterization}

UV-visible (UV-vis) absorption spectra were determined by a Shimadzu UV-2600 spectrophotometer. Transmission electron microscopy (TEM) was acquired by a Hitachi H-800 electron microscope at $200 \mathrm{KV}$ with a CCD camera. A high resolution TEM (HRTEM) was obtained by a JEM-2100F electron microscope at $200 \mathrm{KV}$. The X-ray powder diffraction (XRD) investigation was carried out on a Rigaku X-ray diffractometer. The Au concentration was measured by ICP-OES measurements with a PerkinElmer Optima 3300DV. The zeta potential was measured using a Zetasizer NanoZS (Malvern Instruments). Photothermal imaging photographs were recorded with a Fluke Thermal imager. To analyze the protein activity, SDS-PAGE was applied. AuNRs, RBC membranes, and RBCM-AuNRs were prepared in SDS buffer. After being heated to $100{ }^{\circ} \mathrm{C}$ and kept for $5 \mathrm{~min}$, the sample was loaded into each well of a $10 \%$ SDS polyacrylamide gel to run at $120 \mathrm{~V}$ for $2 \mathrm{~h}$. Subsequently, the resulting polyacrylamide gel was subjected to western blot using an anti-CD47 antibody. A CD47 marker was identified by a Licor Odyssey gel imaging system. Flow cytometric analyses of apoptosis and the cell cycle were measured on a Beckman Coulter FC 500 flow cytometry system. Bright field and fluorescent images of the cells were obtained with an Olympus IX51 inverted fluorescence microscope. 


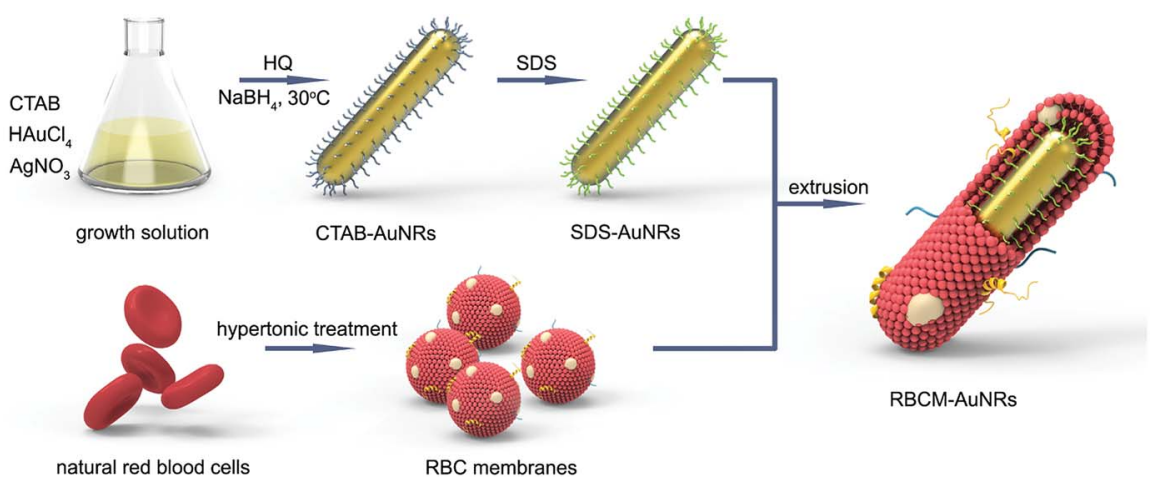

Scheme 1 Schematic illustration of the fabrication process for RBCM-AuNRs.

\section{Results and discussion}

The fabrication process for RBCM-AuNRs is schematically demonstrated in Scheme 1. The fabrication strategy is conducted in three steps: (i) synthesis of AuNRs through a seedless method using HQ as the reductant, (ii) the extraction of RBC membranes, and (iii) the extrusion of RBC membranes with AuNRs. The AuNRs exhibit a good monodispersity and an excellent photothermal conversion efficiency. The RBC membranes wrapping around the AuNRs endow the nanocomposites with dramatically enhanced biocompatibility and a photothermal ablation effect.

In this study, AuNRs were prepared via a seedless method using HQ as the reductant. HQ exhibits a mild reducing capacity and is usually used to fabricate anisotropic structures. In a typical experiment, $50 \mu \mathrm{L}$ of $100 \mathrm{mM} \mathrm{HAuCl}_{4}$ is added into $10 \mathrm{~mL} 0.05 \mathrm{M} \mathrm{CTAB}$ aqueous solution, followed by $100 \mu \mathrm{L}$ of $0.1 \mathrm{M} \mathrm{AgNO}_{3}$. Then $1 \mathrm{~mL}$ of $30 \mathrm{mM} \mathrm{HQ}$ is injected into the growth solution, leading to the reduction of $\mathrm{Au}(\mathrm{III})$ to
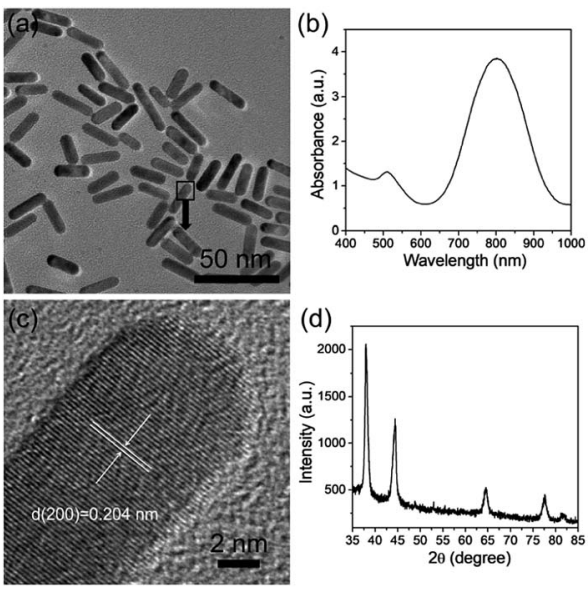

Fig. 1 The characterization of AuNRs that were synthesized at $30^{\circ} \mathrm{C}$ for 3 h. TEM images (a); UV-vis-NIR absorption spectra (b); HRTEM image (c); and XRD pattern (d) of the as-prepared AuNRs. The amount of $0.05 \mathrm{M} \mathrm{CTAB}, 100 \mathrm{mM} \mathrm{HAuCl}_{4}, 0.1 \mathrm{M} \mathrm{AgNO}_{3}, 30 \mathrm{mM} \mathrm{HQ}$, and $10 \mathrm{mM} \mathrm{NaBH}_{4}$ was fixed at $10 \mathrm{~mL}, 50 \mu \mathrm{L}, 100 \mu \mathrm{L}, 1 \mathrm{~mL}$, and $15 \mu \mathrm{L}$, respectively.
$\mathrm{Au}(\mathrm{I})$ with the disappearance of color. ${ }^{29}$ The formation of the AuNRs is initiated by adding ice-cold $\mathrm{NaBH}_{4}$ to produce the small Au nucleus. ${ }^{55}$ When the growth solution is placed into bath water at $30^{\circ} \mathrm{C}$ for $3 \mathrm{~h}$, the color gradually turns brownred, implying that the $\mathrm{Au}$ nucleus grows into rod-like structures by $\mathrm{HQ}$ reducing $\mathrm{Au}(\mathrm{I})$ to $\mathrm{Au}(0) .{ }^{29}$ As shown in the TEM image (Fig. 1a), the products are monodisperse rod-like structures with a size of $28 \times 7 \mathrm{~nm}$, and the corresponding LSPR peaks at $510 \mathrm{~nm}$ and $800 \mathrm{~nm}$, respectively (Fig. 1b). The HRTEM image indicates that the AuNRs are single crystals, with an interplanar distance of $0.204 \mathrm{~nm}$ along the direction of the AuNR growth, consisting of the (200) facets of cubic $\mathrm{Au}^{32}$ (Fig. 1c). The XRD pattern exhibits four diffraction peaks at $38.0,44.5,64.6$, and $77.7^{\circ}$, which correspond to the (111), (200), (220), and (311) facets of face centered cubic Au crystals $^{32}$ (Fig. 1d). The yield of AuNRs calculated by ICP is around $86 \%$, which is much higher than that of ascorbic acid as the reductant in a seed-mediated method. ${ }^{34}$

\subsection{The role of HQ}

HQ can be used as a reductant for the synthesis of Au nanoparticles with different morphologies mainly owing to the conversion of phenol to quinone. In addition, the benzene ring in the structure is also beneficial for synthesizing AuNRs. Several reports have confirmed that aromatic compounds can act as the additives to modify the micellization behavior of CTAB in AuNR synthesis, thus favoring the formation of AuNRs with higher aspect ratios and better size monodispersities. ${ }^{27,29}$ Therefore, HQ is an important factor that influences AuNR growth. To investigate the effect of HQ on the growth of AuNRs, the amount of $30 \mathrm{mM}$ HQ was altered from $0.2 \mathrm{~mL}$ to $1.6 \mathrm{~mL}$. As shown in Fig. 2, when the amount of HQ is changed from $0.2 \mathrm{~mL}$ to $1 \mathrm{~mL}$, the LSPR peaks have a red shift from $700 \mathrm{~nm}$ to $795 \mathrm{~nm}$. The size of the AuNRs increases from $22 \times 9 \mathrm{~nm}$ to 28 $\times 7 \mathrm{~nm}$. Increasing the HQ amount enhances the reducibility of the reaction system, thus providing more Au atoms to block bigger AuNRs. On increasing the amount from further, 1.2 to 1.6 $\mathrm{mL}$, the LSPR peaks do not alter obviously with little effect on the size. This means that $1 \mathrm{~mL}$ of $30 \mathrm{mM} \mathrm{HQ}$ is sufficient for this system. 


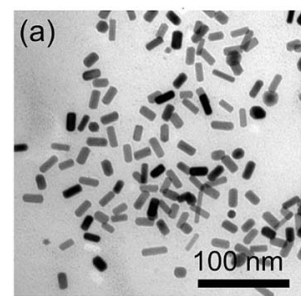

(c)
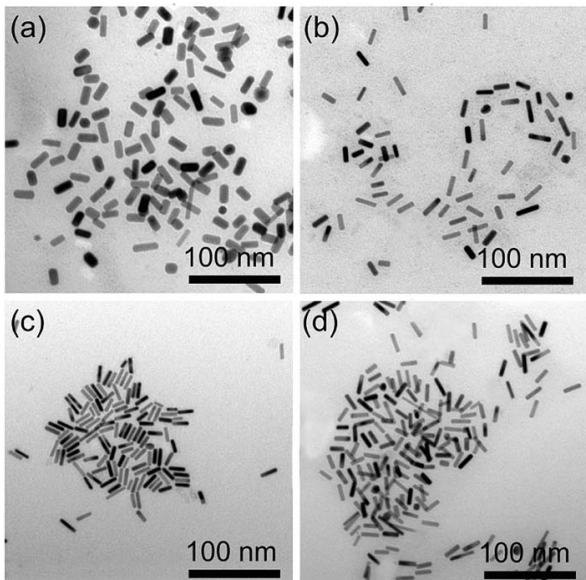

(d)
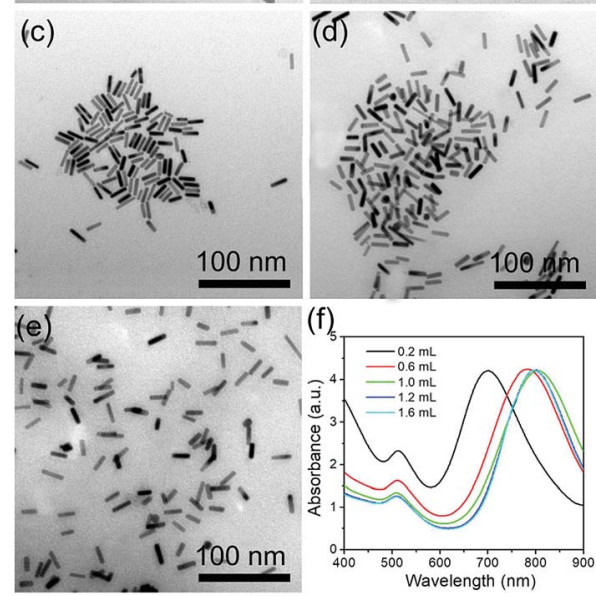

Fig. 2 TEM images (a)-(e) and UV-vis-NIR absorption spectra (f) of the AuNRs that were prepared by altering the amount of $30 \mathrm{mM} \mathrm{HQ}$ solution from 0.2 to $1.6 \mathrm{~mL}$. The amounts of $0.05 \mathrm{M} \mathrm{CTAB}, 100 \mathrm{mM}$ $\mathrm{HAuCl}_{4}, 0.1 \mathrm{M} \mathrm{AgNO}_{3}$, and $10 \mathrm{mM} \mathrm{NaBH}$ were fixed at $10 \mathrm{~mL}, 50 \mu \mathrm{L}$, $100 \mu \mathrm{L}$, and $15 \mu \mathrm{L}$, respectively.

\subsection{Tuning of $\mathrm{LSPR}$ by $\mathrm{AgNO}_{3}$}

$\mathrm{Ag}$ ions are another important parameter for the formation of rod-like $\mathrm{Au}$ nanoparticles. Different amounts of $0.1 \mathrm{M} \mathrm{AgNO}_{3}$ were used to investigate the effect of the $\mathrm{Ag}$ ions in the growth of AuNRs. When $60 \mu \mathrm{L}$ of $\mathrm{AgNO}_{3}$ solution is added into the growth solution, AuNRs with the size of $16 \times 6 \mathrm{~nm}$ were prepared, with the corresponding LSPR peak at around $710 \mathrm{~nm}$ (Fig. 3a and e). When the amount of $\mathrm{AgNO}_{3}$ increases to 80 and $100 \mu \mathrm{L}$, the LSPR peaks shift to 755 and $800 \mathrm{~nm}$, respectively (Fig. 3e), and the size of AuNRs increases to $23 \times 7 \mathrm{~nm}$ and $28 \times 7 \mathrm{~nm}$ (Fig. $3 \mathrm{~b}$ and c). With increasing the amount of $\mathrm{AgNO}_{3}$ to 120 and $160 \mu \mathrm{L}$, the LSPR peaks show a further red shift to 826 and $840 \mathrm{~nm}$, respectively. And the size of the AuNRs increases to $33 \times 7 \mathrm{~nm}$ and $35 \times 8 \mathrm{~nm}$, respectively (Fig. $3 \mathrm{~d}$ and e). The current research has proven that a high $\mathrm{AgNO}_{3}$ concentration facilitates the longitudinal growth of AuNRs by increasing the ionic strength of the growth solution.

\subsection{The role of $\mathrm{CTAB}$}

$\mathrm{CTAB}$ is a necessary factor that influences the production of the AuNRs by selective adsorption on the (110) and (100) facets of the $\mathrm{Au}$ crystals, thus facilitating $\mathrm{Au}$ atom deposition on both ends of the AuNRs. Fig. 4 shows the effect of CTAB on AuNR growth. As the concentration of CTAB is fixed as low as $0.01 \mathrm{mM}$, abundant spherical structures with poor AuNRs are observed with the LSPR peak at $520 \mathrm{~nm}$, which is a typical absorption peak for $20 \mathrm{~nm} \mathrm{Au}$ nanoparticles (Fig. 4a and f).

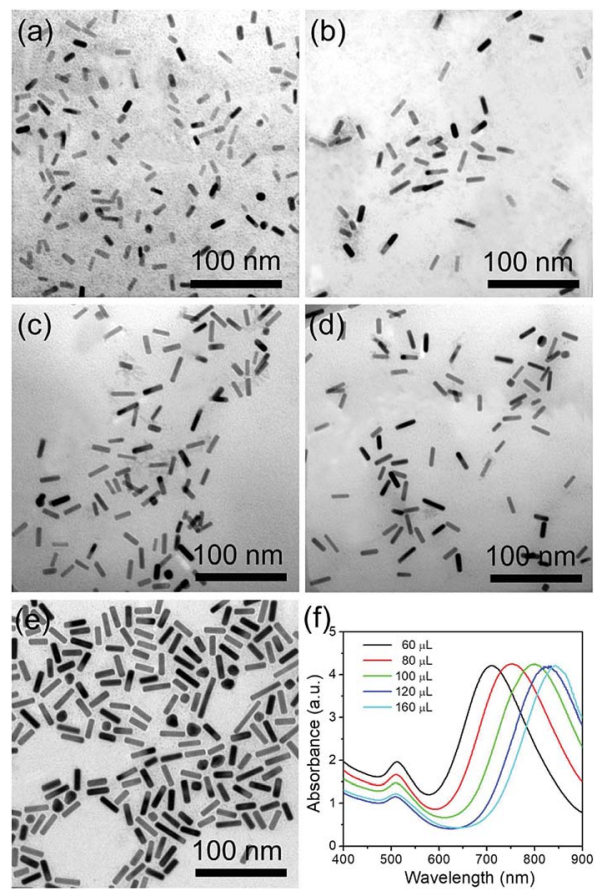

Fig. 3 TEM images (a)-(e) and UV-vis-NIR absorption spectra (f) of the AuNRs that were prepared by altering the amount of $0.1 \mathrm{M} \mathrm{AgNO}_{3}$ solution from 60 to $160 \mu \mathrm{L}$. The amounts of $0.05 \mathrm{M} \mathrm{CTAB}, 100 \mathrm{mM}$ $\mathrm{HAuCl}_{4}, 30 \mathrm{mM} \mathrm{HQ}$, and $10 \mathrm{mM} \mathrm{NaBH}_{4}$ were fixed at $10 \mathrm{~mL}, 50 \mu \mathrm{L}, 1$ $\mathrm{mL}$, and $15 \mu \mathrm{L}$, respectively.

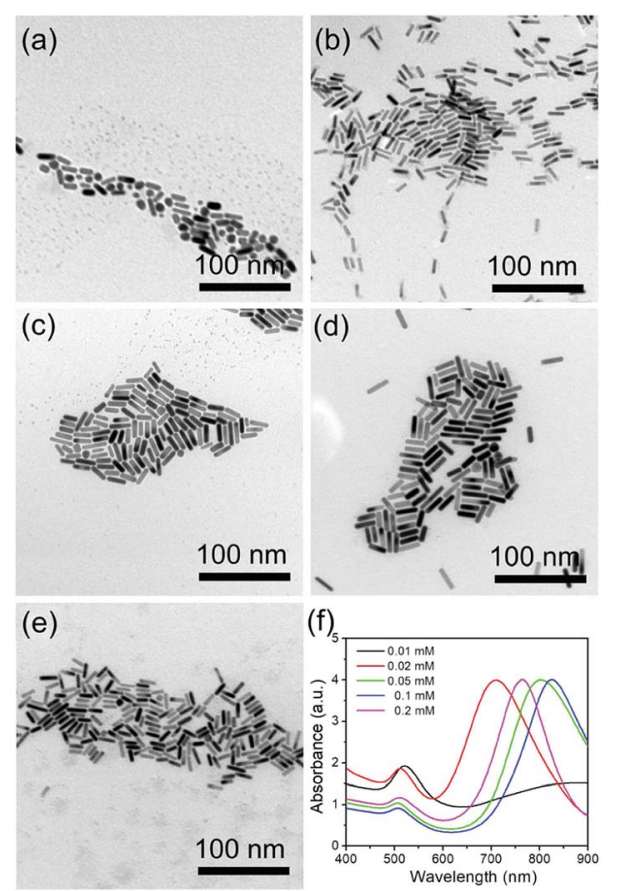

Fig. 4 TEM images (a) - (e) and UV-vis-NIR absorption spectra (f) of the AuNRs that were prepared by altering the concentration of CTAB from 0.01 to $0.2 \mathrm{mM}$. The volume of the CTAB solution was fixed at $10 \mathrm{~mL}$. The amounts of $100 \mathrm{mM} \mathrm{HAuCl}_{4}, 0.1 \mathrm{M} \mathrm{AgNO}_{3}, 30 \mathrm{mM} \mathrm{HQ}$, and $10 \mathrm{mM}$ $\mathrm{NaBH}_{4}$ were fixed at $50 \mu \mathrm{L}, 100 \mu \mathrm{L}, 1 \mathrm{~mL}$, and $15 \mu \mathrm{L}$, respectively. 
When the concentration of CTAB is adjusted from 0.02 to $0.1 \mathrm{mM}$, the LSPR peak red shifts from 715 to $825 \mathrm{~nm}$, with the size of the high quality AuNRs increasing from $18 \times 7$ to $33 \times$ $7 \mathrm{~nm}$ (Fig. 4b-d and f). On further increases in the concentration of CTAB to $0.2 \mathrm{mM}$, the LSPR peak exhibits a blue shift to $760 \mathrm{~nm}$ (Fig. 4e and f). The influence of CTAB on the AuNR size is mainly summarized as that when the amount of CTAB is too low, the adsorption of CTAB on the sides of the AuNRs is inadequate to suppress the deposition of Au. When the amount of CTAB is too high, CTAB will absorb not only on the side but also on the ends, thus lowering the Au atom facet-selectivity.

\subsection{The role of $\mathrm{NaBH}_{4}$}

In this protocol, $\mathrm{NaBH}_{4}$ acts as an initiator to trigger the AuNR growth by generating an Au nucleus. When the growth solution has no $\mathrm{NaBH}_{4}$, no AuNRs are observed in TEM observations (Fig. S1a $\dagger$ ). This indicates that the $\mathrm{Au}$ nucleus reduced by $\mathrm{NaBH}_{4}$ is vital for forming AuNRs. When the amount of $10 \mathrm{mM}$ $\mathrm{NaBH}_{4}$ increases to $60 \mu \mathrm{L}$, a mass of spherical Au nanoparticles appears, which is mainly attributed to the strong reducibility of $\mathrm{NaBH}_{4}$ to consume almost all of the Au nucleus. The remaining $\mathrm{Au}$ cannot support the AuNR growth any longer (Fig. S1b $\dagger$ ). So a moderate $\mathrm{NaBH}_{4}$ content is suitable for the synthesis of high quality AuNRs.

\subsection{The effect of reaction temperature and $\mathrm{HAuCl}_{4}$}

Reaction temperature and $\mathrm{HAuCl}_{4}$ also have an evident influence on AuNR growth. The same growth solutions mixed with $\mathrm{CTAB}, \mathrm{HAuCl}_{4}, \mathrm{AgNO}_{3}, \mathrm{HQ}$, and $\mathrm{NaBH}_{4}$ were incubated in bath water fixed at different temperature. As shown in Fig. S2, $\uparrow$ as the temperature rises from 25 to $60{ }^{\circ} \mathrm{C}$, the size of the AuNRs decreases from $33 \times 7$ to $24 \times 9 \mathrm{~nm}$. And the corresponding LSPR peak shows a blue-shift from 820 to $750 \mathrm{~nm}$, which indicates a shortening of the long axis. The high temperature can accelerate the reaction speed to lower the Au facet-selectivity, which facilitates the formation of short AuNRs. Thus, a mild temperature can decrease the growth rate, which means it is easier to control the growth of AuNRs to obtain high quality AuNRs of a longer size.

As to the influence of the $\mathrm{HAuCl}_{4}$ concentration, different amounts of $\mathrm{HAuCl}_{4}$ were tuned to investigate the effect on the AuNR growth. When the amount of $100 \mathrm{mM} \mathrm{HAuCl}_{4}$ is fixed at $25 \mu \mathrm{L}$, the amount of $\mathrm{HAuCl}_{4}$ is too low to support the AuNR growth. So the products are the mixture of spherical particles and AuNRs (Fig. S3a $\dagger$ ). And the absorbance spectra show an obvious peak at $520 \mathrm{~nm}$, which corresponds to spherical Au nanoparticles $20 \mathrm{~nm}$ in diameter. With further enhancing the amount of $\mathrm{HAuCl}_{4}$ from 50 to $100 \mu \mathrm{L}$, the corresponding LSPR peak exhibits a blue shift from $800 \mathrm{~nm}$ to $615 \mathrm{~nm}$ (Fig. S3b-d $\dagger$ ). The shorter and wider AuNRs that appear with $100 \mu \mathrm{L}$ of $\mathrm{HAuCl}_{4}$ $(26 \times 16 \mathrm{~nm})$ result from the excessive $\mathrm{Au}$ in the growth solution binding with $\mathrm{CTAB}$, supplying more $\mathrm{Au}$ deposited on the AuNRs. The low facet selectivity leads to the growth of wider AuNRs.

\subsection{Photothermal properties of AuNRs}

To demonstrate the photothermal properties of AuNRs, AuNRs $(28 \times 7 \mathrm{~nm})$ with the LSPR peak located at $800 \mathrm{~nm}$ were selected for $808 \mathrm{~nm}$ laser irradiation. As shown in Fig. 5a, the temperature variations of the different concentrations of the AuNRs under $1.0 \mathrm{~W} \mathrm{~cm}^{-2}$ were recorded. The same volume of deionized water as the negative control only increased by $5{ }^{\circ} \mathrm{C}$ under 10 min of irradiation, while the AuNRs with concentrations higher than $20 \mu \mathrm{g} \mathrm{mL}{ }^{-1}$ increased by more than $20{ }^{\circ} \mathrm{C}$, beneficial for cancer cell photothermal destruction (Fig. 5a). In addition, with a laser power density increase from $0.5 \mathrm{~W} \mathrm{~cm}^{-2}$ to $1.5 \mathrm{~W} \mathrm{~cm}^{-2}$, the solution of $40 \mu \mathrm{g} \mathrm{mL}^{-1}$ AuNRs rises to a higher temperature (Fig. 5b). The photothermal stability of the AuNRs is operated by irradiation with $1.5 \mathrm{~W} \mathrm{~cm}^{-2} 808 \mathrm{~nm}$ for $10 \mathrm{~min}$ from an ambient temperature. The top temperature is almost unchanged after four cycles (Fig. 5c). And the photothermal transduction efficiency $(\eta)$ was calculated by recording the temperature variation from the ambient temperature to the top temperature and the decrement when the irradiation laser was shut off (Fig. 5d). The temperature change during the irradiation was also recorded by an IR thermal camera (Fig. 5e). Following the method developed by $\mathrm{Hu}$ et al., ${ }^{56}$ the photothermal transduction efficiency of AuNRs with the LSPR peak located at $800 \mathrm{~nm}(28 \times 7 \mathrm{~nm})$ was $80 \%$ (Fig. S4 $\dagger)$, which is much higher than those of AuNRs prepared by other means. ${ }^{19,29,37}$ The high photothermal transduction efficiency

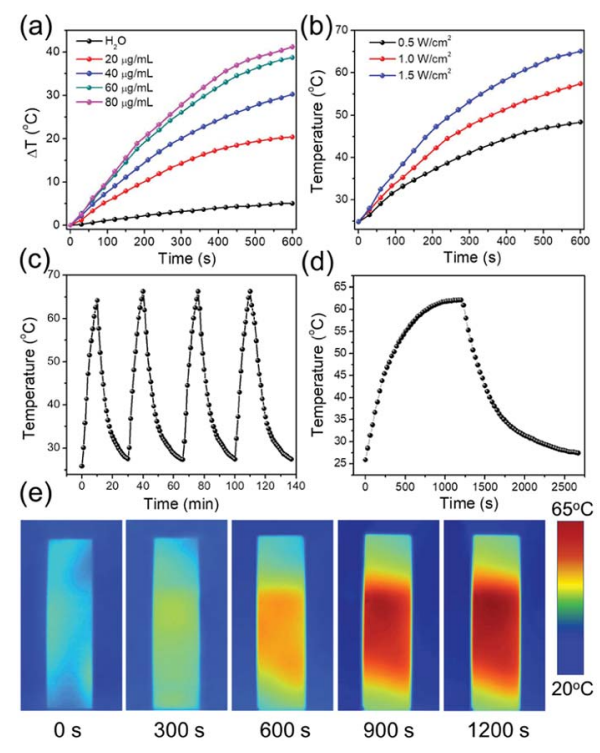

Fig. 5 (a) The dependence of the temperature increment on the concentration of AuNRs. The power density of the $808 \mathrm{~nm}$ laser was fixed at $1 \mathrm{~W} \mathrm{~cm}^{-2}$. (b) The dependence of the temperature increment on the power density of the $808 \mathrm{~nm}$ laser. The concentration of AuNRs was fixed at $40 \mu \mathrm{g} \mathrm{mL}^{-1}$. (c) The temperature variation of a $40 \mu \mathrm{g} \mathrm{mL}^{-1}$ AuNR solution as irradiated by the $1.5 \mathrm{~W} \mathrm{~cm}^{-2} 808 \mathrm{~nm}$ laser for four cycles. (d) The temporal temperature variation of AuNRs. The solution was irradiated by a $1.5 \mathrm{~W} \mathrm{~cm} \mathrm{~cm}^{-2} 808 \mathrm{~nm}$ laser until a steady state temperature, and cooled to room temperature under an ambient environment. (e) IR thermal images of a $40 \mu \mathrm{g} \mathrm{mL}^{-1}$ AuNR solution under the irradiation of a $1.5 \mathrm{~W} \mathrm{~cm}^{-2} 808 \mathrm{~nm}$ laser for $1200 \mathrm{~s}$. In all the experiments, AuNRs with an LSPR peak at $800 \mathrm{~nm}$ were used. 
was attributed to the LSPR peak appropriately matching with the $808 \mathrm{~nm}$ laser wavelength.

\subsection{Fabrication and characterization of RBCM-AuNRs}

In order to coat with RBC membranes, the as-prepared AuNRs stabilized with CTAB (CTAB-AuNRs) were first fabricated with an anionic surfactant SDS to replace the CTAB on the surface of the AuNRs. Otherwise, once the positively charged CTAB-AuNRs mix with negatively charged RBC membranes, the RBC membranes can directly absorb on the CTAB-AuNRs, which will result in the proteins on the surface of the $\mathrm{RBC}$ membranes being trapped in the interior and interfere with the proteins camouflaging the AuNRs. ${ }^{57}$ Therefore, SDS is chosen as the negative ligand to change the surface potential of the AuNRs from $80 \mathrm{mV}$ to $-10 \mathrm{mV}$ (Fig. 6a). Once mixed with $\mathrm{RBC}$ membranes through a $200 \mathrm{~nm}$ polycarbonate porous membrane, the proteins on the RBC membranes can be arranged externally by electrostatic repulsion and the zeta potential of RBCM-AuNRs is $-26 \mathrm{mV}$, almost close to that of RBC membranes ( $-35 \mathrm{mV}$ ) (Fig. 6a). The TEM image shows a coating on the surface on the AuNRs (Fig. 6b). By comparison with the TEM image of the original Au NRs with CTAB stabilization (Fig. 6c), the approximate $6 \mathrm{~nm}$ thick shell is clearly observed. The coating thickness is consistent with the reported $^{58}$ of 5-10 nm, indicating a successful RBC membrane coating. CD47 is a well-documented protein marker firmly

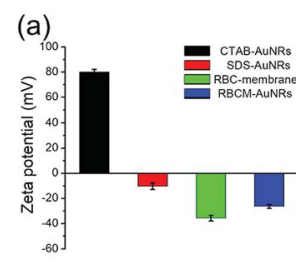

(c)
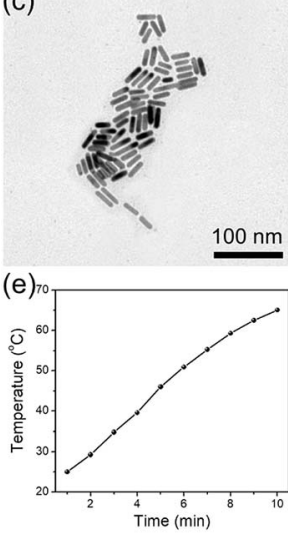

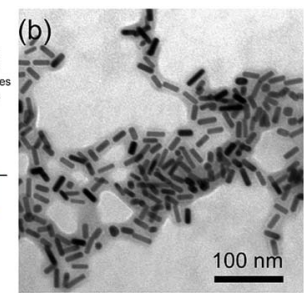

(d)
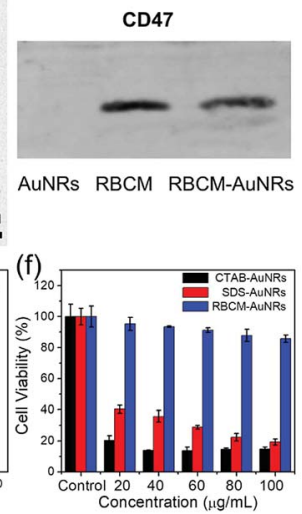

Fig. 6 (a) Zeta potential of CTAB-AuNRs, SDS-AuNRs, RBC membranes, and RBCM-AuNRs. TEM images of RBCM-AuNRs (b) and the original AuNRs (c). (d) Western blot analysis of the CD47 expression on AuNRs, RBC membranes and RBCM-AuNRs. (e) The temperature variation of a $40 \mu \mathrm{g} \mathrm{mL} \mathrm{m}^{-1} \mathrm{RBCM}$-AuNR solution under the $808 \mathrm{~nm}$ laser at a density of $1.5 \mathrm{~W} \mathrm{~cm}^{-2}$ for $10 \mathrm{~min}$. (f) In vitro cytotoxicity of CTAB-AuNRs, SDS-AuNRs, and RBCM-AuNRs against A549 cells for concentrations ranging from 20 to $100 \mu \mathrm{g} \mathrm{mL}^{-1}$. embedded in RBC membranes, and is usually characteristic for RBCs. CD47 and its analogs have been found to help RBCs escaping immune clearance. The western blot assay was employed to find CD47 at a near equivalent degree on RBCMAuNRs and RBC membranes (Fig. 6d), which demonstrates the successful integration of RBC membranes with AuNRs. And after the RBC membrane coating, the excellent photothermal conversion effect AuNRs was studied. As shown in Fig. 6e, the temperature of a $40 \mu \mathrm{g} \mathrm{mL^{-1 }}$ RBCM-AuNR solution under the $808 \mathrm{~nm}$ laser at a density of $1.5 \mathrm{~W} \mathrm{~cm}^{-2}$ for $10 \mathrm{~min}$ can increase to $65.1{ }^{\circ} \mathrm{C}$, which is almost equal to that of the same amount of AuNRs. This means that the RBCM-AuNRs exhibit an excellent photothermal conversion effect. The stability of the nanomaterials is crucial for biological applications. The physiological stability of RBCM-AuNRs was studied by incubating RBCMAuNRs in PBS for 2 days. The RBC membrane coating on the surface of the AuNRs can still be observed under TEM (Fig. S5 $\dagger$ ), which indicates a good physiological stability of RBCM-AuNRs in the biological environment. The cytotoxicity of the RBCMAuNRs was detected by a CCK-8 assay after incubation with A549 of different concentrations for 24 h. As shown in Fig. 6f, the RBCM-AuNRs exhibit a low toxicity for A549 cells. Even when the concentration of RBCM-AuNRs is as high as $100 \mu \mathrm{g}$ $\mathrm{mL}^{-1}$, the cell viability is still more than $80 \%$, while $20 \mu \mathrm{g} \mathrm{mL}$ CTAB-AuNRs and $40 \mu \mathrm{g} \mathrm{mL}^{-1}$ SDS-AuNRs almost kill all the cells with the toxicity of the surfactants. ${ }^{39}$ These cell viability results confirm that RBC membranes dramatically reduce the cytotoxicity of the AuNRs, which has a negligible effect on cell proliferation.

In order to further confirm that RBC membranes can improve the biocompatibility of the AuNRs, a study of cell apoptosis was carried by flow cytometry. As shown in Fig. 7, the cells in areas B1-B4 represent death, late apoptosis, viability, and early apoptosis, respectively. Compared with the control group, the A549 cells incubated with $80 \mu \mathrm{g} \mathrm{mL}^{-1}$ RBCM-AuNRs for $24 \mathrm{~h}$ only show $1.2 \%$ cell apoptosis, and more than $98.1 \%$ cells are alive (Fig. 7a). The results validate the excellent biocompatibility of the RBCM-AuNRs. A cell cycle analysis was further implemented to verity the biocompatibility of RBCMAuNRs. As shown in Fig. 7b, 73.36\%, 18.43\% and $8.21 \%$ of
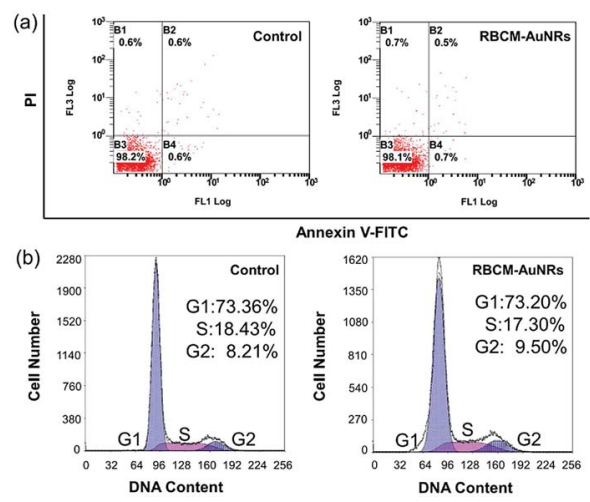

Fig. 7 (a) Flow cytometric analysis of apoptosis and (b) cell cycle analysis by staining the DNA in A549 cells with PI induced by $24 \mathrm{~h}$ incubation with $80 \mu \mathrm{g} \mathrm{mL}^{-1}$ RBCM-AuNRs. 
the cells in the control group are found to be in the G1, S, and G2 phases, respectively. In contrast, for the A549 cells incubated with $80 \mu \mathrm{g} \mathrm{mL}{ }^{-1}$ RBCM-AuNRs, $73.20 \%, 17.30 \%$ and $9.50 \%$ of the cells are found to be in the G1, S, and G2 phases, respectively. The results demonstrate that $80 \mu \mathrm{g} \mathrm{mL}{ }^{-1} \mathrm{RBCM}-A u N R s$ do not affect cell growth cycles, which shows a good biocompatibility. Taken together, these results confirm that RBC membranes dramatically reduce the cytotoxicity of the AuNRs, which benefits application in the photothermal therapy of tumor cells.

\subsection{In vitro PTT studies}

The in vitro photothermal therapy effect is studied by calculating the cell viability under an $808 \mathrm{~nm}$ laser irradiation. The A549 cells were first incubated with different concentrations of RBCM-AuNRs for $4 \mathrm{~h}$, followed by $808 \mathrm{~nm}$ laser irradiation of $1.5 \mathrm{~W} \mathrm{~cm} \mathrm{~cm}^{-2}$ for $8 \mathrm{~min}$. The CCK- 8 results display that cell viability decreases significantly with the increase of RBCMAuNR concentration. Under $1.5 \mathrm{~W} \mathrm{~cm}^{-2}$ laser irradiation for $8 \mathrm{~min}$, more than $67 \%$ of the A549 cells incubated with $20 \mu \mathrm{g}$ $\mathrm{mL}^{-1}$ RBCM-AuNRs are killed. And the cell viability decreases to $12 \%$ as the concentration of RBCM-AuNRs increases to $40 \mu \mathrm{g}$ $\mathrm{mL}^{-1}$. And when the concentration of RBCM-AuNRs increases to more than $60 \mu \mathrm{g} \mathrm{mL}^{-1}$, the cell viability is only less than $10 \%$. As a contrast, the A549 cells have no apoptosis in the absence of RBCM-AuNRs under $1.5 \mathrm{~W} \mathrm{~cm}^{-2}$ laser irradiation for $8 \mathrm{~min}$ (Fig. 8a). This illustrates that laser irradiation without RBCMAuNRs cannot lead to cell apoptosis. The cells die from high temperature induced laser irradiation to the RBCM-AuNRs. The effect of photothermal killing also depends on the laser power density. The cell viability incubated with $40 \mu \mathrm{g} \mathrm{mL}^{-1} \mathrm{RBCM}$ AuNRs decreases dramatically when the laser power density

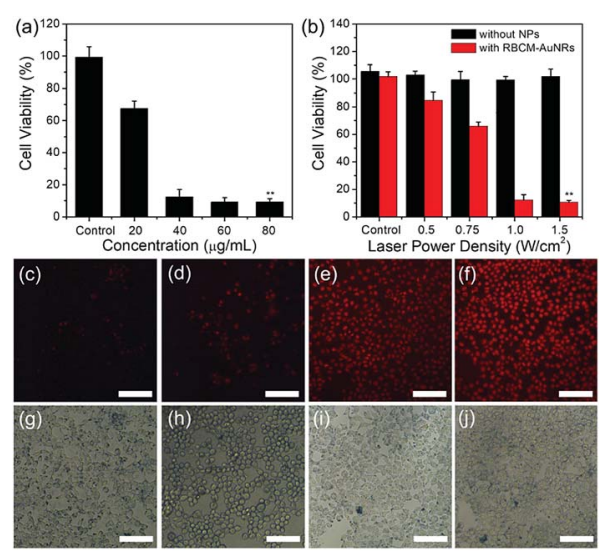

Fig. 8 (a) A549 cell viabilities versus the concentration of RBCMAuNRs, which was studied using $1.5 \mathrm{~W} \mathrm{~cm}^{-2} 808 \mathrm{~nm}$ laser irradiation for $8 \mathrm{~min}$. (b) A549 cell viabilities after $808 \mathrm{~nm}$ laser irradiation with power densities of $0.5,0.75,1$, and $1.5 \mathrm{~W} \mathrm{~cm}^{-2}$ for $8 \mathrm{~min}$. (c-f) Fluorescent and $(\mathrm{g}-\mathrm{j})$ bright field images of $\mathrm{A} 549$ cells after irradiation by an $808 \mathrm{~nm}$ laser with a power density of 0.5 (c and g), 0.75 ( $d$ and h), 1 (e and i), and 1.5 (f and j) $\mathrm{W} \mathrm{cm}^{-2}$ for $8 \mathrm{~min}$. The scale bar is $100 \mu \mathrm{m}$. The A549 cells are first incubated with $40 \mu \mathrm{g} \mathrm{mL}^{-1} \mathrm{RBCM}$-AuNRs for $4 \mathrm{~h}$. Data are shown as means \pm standard error of the means, $* p<0.05$ and $* * p<0.01$. increases from 0.5 to $1.5 \mathrm{~W} \mathrm{~cm}^{-2}$ (Fig. 8b). When the power density is $0.5 \mathrm{~W} \mathrm{~cm}^{-2}$, only less than $16 \%$ of the A549 cells are destroyed. When the laser power density increases to $1.0 \mathrm{~W}$ $\mathrm{cm}^{-2}$, the cell viability dramatically decreases to $12 \%$ (Fig. $8 \mathrm{~b}$ ). The high cell apoptosis ratio at such low power densities indicates the excellent performance of RBCM-AuNRs in the photothermal killing of A549 cells. When the laser power density further increases to $1.5 \mathrm{~W} \mathrm{~cm}^{-2}$, the viability of A549 cells is only $10 \%$. While without the laser irradiation, the viability of A549 cells incubated with $40 \mu \mathrm{g} \mathrm{mL} \mathrm{mL}^{-1}$ RBCM-AuNRs keeps at 95\% (Fig. 7f). The control experiment indicates that the laser irradiation upon the A549 cells in the absence of RBCM-AuNRs has no influence on the viability (Fig. 8b). And the photothermal killing effect of the RBCM-AuNRs in vitro is intuitively observed by apoptosis staining under fluorescence microscopy. The apoptosis cells are stained by PI, which can penetrate dead cells only. With the increase of power density, the stained cells obviously increase (Fig. 8c-j). Additionally, almost no cells have been damaged under laser irradiation without RBCM-AuNR treatment (Fig. 8b), which confirms that the cell apoptosis results from the photothermal effect of RBCM-AuNRs. In all, the photothermal apoptosis effect demonstrates the excellent performance of RBCM-AuNRs.

\section{Conclusions}

In summary, we have developed an effective strategy to prepare AuNRs through a seedless method employing HQ as the reductant. The RBC membranes are further utilized as coating materials to lower the nanotoxicity of the as-prepared AuNRs. By tuning the amount of $\mathrm{HQ}, \mathrm{AgNO}_{3} \mathrm{CTAB}, \mathrm{HAuCl}_{4}$, and $\mathrm{NaBH}_{4}$, and the reaction temperature, the LSPR peaks of the AuNRs can be adjusted from 650 to $840 \mathrm{~nm}$. The photothermal transduction efficiency of the as-prepared AuNRs can reach 80\% under $808 \mathrm{~nm}$ laser irradiation, which shows the potential as photothermal agents. The coating of RBC membranes on the surfaces of AuNRs does not damage the activity of the proteins of the RBC membranes, but obviously lowers the toxicity of AuNRs. In vitro experiments indicate that the RBCM-AuNRs possess an excellent photothermal killing effect. Benefiting from the RBC membrane camouflage, the RBCM-AuNRs show a prolonged circulation lifetime, which favors the accumulation of AuNRs in the tumor site. We believe that these biomimetic materials are promising in tumor theranostics.

\section{Conflicts of interest}

There are no conflicts to declare.

\section{Acknowledgements}

This work was supported by NSFC (51703077, 51603084, 21374042), the Natural Science Foundation of Jilin Province (20180520023JH), and the Fundamental Research Funds for the Central Universities. 


\section{References}

1 P. K. Jain, X. H. Huang, I. H. El-Sayed and M. A. El-Sayed, Acc. Chem. Res., 2008, 41, 1578.

2 M. P. Melancon, M. Zhou and C. Li, Acc. Chem. Res., 2011, 44, 947.

3 G. Chen, I. Roy, C. Yang and P. N. Prasad, Chem. Rev., 2016, 116, 2826.

4 E.-K. Lim, T. Kim, S. Paik, S. Haam, Y.-M. Huh and K. Lee, Chem. Rev., 2015, 115, 327.

5 Z. Zha, X. Yue, Q. Ren and Z. Dai, Adv. Mater., 2013, 25, 777.

6 L. Xu, L. Cheng, C. Wang, R. Peng and Z. Liu, Polym. Chem., 2014, 5, 1573.

7 J. T. Robinson, S. M. Tabakman, Y. Liang, H. Wang, H. S. Casalongue, D. Vinh and H. Dai, J. Am. Chem. Soc., 2011, 133, 6825.

8 M. Chu, Y. Shao, J. Peng, X. Dai, H. Li, Q. Wu and D. Shi, Biomaterials, 2013, 34, 4078.

9 Q. Tian, Q. Wang, K. X. Yao, B. Teng, J. Zhang, S. Yang and Y. Han, Small, 2014, 10, 1063.

10 M. Chu, Y. Shao, J. Peng, X. Dai, H. Li, Q. Wu and D. Shi, Biomaterials, 2013, 34, 4078.

11 J. Li, W. J. Wang., L. Zhao, L. Rong, S. J. Lan, H. C. Sun, H. Zhang and B. Yang, ACS Appl. Mater. Interfaces, 2015, 7, 11613.

12 M. Lin, C. Guo, J. Li, D. Zhou, K. Liu, X. Zhang, T. Xu, H. Zhang, L. Wang and B. Yang, ACS Appl. Mater. Interfaces, 2014, 6, 5860.

13 W. Zhou, X. Gao, D. Liu and X. Chen, Chem. Rev., 2015, 115, 10575.

14 Y. N. Xia, W. Y. Li, C. M. Cobley, J. Y. Chen, X. H. Xia, Q. Zhang, M. X. Yang, E. C. Cho and P. K. Brown, Acc. Chem. Res., 2011, 44, 914.

15 H. Liu, D. Chen, L. Li, T. Liu, L. Tan, X. Wu and F. Tang, Angew. Chem., Int. Ed., 2011, 50, 891.

16 P. Vijayaraghavan, C.-H. Liu, R. Vankayala, C.-S. Chiang and K. C. Hwang, Adv. Mater., 2014, 26, 6689.

17 M. Cheng, H. Wang, Z. Zhang, N. Li, X. Fang and S. Xu, ACS Appl. Mater. Interfaces, 2014, 6, 1569.

18 H. Chen, L. Shao, Q. Li and J. Wang, Chem. Soc. Rev., 2013, 42, 2679.

19 X. Huang, S. Neretina and M. A. El-Sayed, Adv. Mater., 2009, 21, 4880 .

20 Z. Zhang, J. Wang, X. Nie, T. Wen, Y. Ji, X. Wu, Y. Zhao and C. Chen, J. Am. Chem. Soc., 2014, 136, 7317.

21 Y.-T. Chang, P.-Y. Liao, H.-S. Sheu, Y.-J. Tseng, F.-Y. Cheng and C.-S. Yeh, Adv. Mater., 2012, 24, 3309.

22 N. R. Jana, L. Gearheart and C. J. Murphy, Adv. Mater., 2001, 13, 1389.

23 J. Song, L. Pu, J. Zhou, B. Duan and H. Duan, ACS Nano, 2013, 7, 9947.

24 B. Nikoobakht and M. A. El-Sayed, Chem. Mater., 2003, 15, 1957.

25 T. H. Ha, H.-J. Koo and B. H. Chung, J. Phys. Chem. C, 2007, 111, 1123.

26 G. Su, C. Yang and J.-J. Zhu, Langmuir, 2015, 31, 817.
27 X. Ye, L. Jin, H. Caglayan, J. Chen, G. Xing, C. Zheng, V. Doan-Nguyen, Y. Kang, N. Engheta, C. R. Kagan and C. B. Murray, ACS Nano, 2012, 6, 2804.

28 A. Gole and C. J. Murphy, Chem. Mater., 2004, 16, 3633.

29 W. Wang, J. Li, S. Lan, L. Rong, Y. Liu, Y. Sheng, H. Zhang and B. Yang, Nanotechnology, 2016, 27, 165601.

30 X. Xu, Y. Zhao., X. Xue, S. Huo, F. Chen, G. Zou and X.-J. Liang, J. Mater. Chem. A, 2014, 2, 3528.

31 M. R. K. Ali, B. Snyder and M. A. El-Sayed, Langmuir, 2012, 28, 9807.

32 J. Li, J. Wu, X. Zhang, Y. Liu, D. Zhou, H. Z. Sun, H. Zhang and B. Yang, J. Phys. Chem. C, 2011, 115, 3630.

33 L. Vigderman and E. R. Zubarev, Chem. Mater., 2013, 25, 1450-1457.

34 C. J. Orendorff and C. J. Murphy, J. Phys. Chem. B, 2006, 110, 3990.

35 S. D. Perrault and W. C. W. Chan, J. Am. Chem. Soc., 2009, 131, 17042.

36 X. Ye, L. Jin, H. Caglayan, J. Chen, G. Xing, C. Zheng, V. Doan-Nguyen, Y. Kang, N. Engheta, C. R. Kagan and C. B. Murray, ACS Nano, 2012, 6, 2804.

37 J. Song, X. Yang, O. Jacobson, L. Lin, P. Huang, G. Niu, Q. Ma and X. Chen, ACS Nano, 2015, 9, 9199.

38 J. Wang, B. Dong, B. Chen, Z. Jiang and H. Song, Dalton Trans., 2012, 41, 11134.

39 S. Liu, L. Wang, M. Lin, D. Wang, Z. Song, S. Li, R. Ge, X. Zhang, Y. Liu, Z. Li, H. Sun, B. Yang and H. Zhang, ACS Appl. Mater. Interfaces, 2017, 9, 44293.

40 Z. J. Zhang, L. M. Wang, J. Wang, X. M. Jiang, X. H. Li, Z. J. Hu, Y. L. Ji, X. C. Wu and C. Y. Chen, Adv. Mater., 2012, 24, 1418.

41 L. Rao, L.-L. Bu, J.-H. Xu, B. Cai, G.-T. Yu, X. Yu, Z. He, Q. Huang, A. Li, S.-S. Guo, W.-F. Zhang, W. Liu, Z.-J. Sun, H. Wang, T.-H. Wang and X.-Z. Zhao, Small, 2015, 11, 6225.

42 T. Ishida, M. Ichihara, X. Wang, K. Yamamoto, J. Kimura, E. Majima and H. Kiwada, J. Controlled Release, 2006, 112, 15.

43 H. Sun, J. Su, Q. Meng, Q. Yin, L. Chen, W. Gu, P. Zhang, Z. Zhang, H. Yu, S. Wang and Y. Li, Adv. Mater., 2016, 28, 9581.

44 W. Gao, C.-M. J. Hu, R. H. Fang, B. T. Luk, J. Su and L. Zhang, Adv. Mater., 2013, 25, 3549-3553.

45 A. Parodi, N. Quattrocchi, A. L. van de Ven, C. Chiappini, M. Evangelopoulos, J. O. Martinez, B. S. Brown, S. Z. Khaled, I. K. Yazdi, M. V. Enzo, L. Isenhart, M. Ferrari and E. Tasciotti, Nat. Nanotechnol., 2013, 8, 61.

46 X. Wei, J. Gao., R. H. Fang, B. T. Luk, A. V. Kroll, D. Dehaini, J. Zhou, H. W. Kim, W. Gao, W. Lu and L. Zhang, Biomaterials, 2016, 111, 116.

47 Z. Chen, P. Zhao, Z. Luo, M. Zheng, H. Tian, P. Gong, G. Gao, H. Pan, L. Liu, A. Ma, H. Cui, Y. Ma and L. Cai, ACS Nano, 2016, 10, 10049.

48 L. Rao, L.-L. Bu, Q.-F. Meng, B. Cai, W.-W. Deng and A. Li, Adv. Funct. Mater., 2017, 27, 1604774.

49 L. Rao, B. Cai, L. L. Bu, Q. Q. Liao, S. S. Guo and X. Z. Zhao, ACS Nano, 2017, 11, 3496.

50 P. Zhang, G. Liu and X. Chen, Nano Today, 2017, 13, 7. 
51 C. Gao, Z. Lin, B. Jurado-Sánchez, X. Lin, Z. Wu and Q. He, Small, 2016, 30, 4056.

52 P.-A. Oldenborg, A. Zheleznyak, Y.-F. Fang, C. F. Lagenaur, H. D. Gresham and F. P. Lindberg, Science, 2000, 288, 2051.

53 L. Rao, L. L. Bu, J. H. Xu, B. Cai, G. T. Yu and X. Yu, Small, 2015, 11, 6225.

54 C. M. Hu, L. Zhang, S. Aryal, C. Cheung, R. H. Fang and L. Zhang, Proc. Natl. Acad. Sci. U. S. A., 2011, 108, 10980.
55 L. Zhang, K. Xia, Z. Lu, G. Li, J. Chen, Y. Deng, S. Li and F. Zhou, Chem. Mater., 2014, 26, 1794.

56 Q. Tian, F. Jiang, R. Zou, Q. Liu, Z. Chen, M. Zhu, S. Yang, J. Wang, J. Wang and J. Hu, ACS Nano, 2011, 5, 9761-9771.

57 T. Jiang, B. Zhang, S. Shen, Y. Tuo, Z. Luo, Y. Hu, Z. Pang and X. Jiang, ACS Appl. Mater. Interfaces, 2017, 9, 31497.

58 X. Wang, H. Li, X. Liu, T. Ye, H. Guo, T. Jiang, Z. Luo, K. Jin, X. Kuai, Y. Liu, Z. Pang, W. Yang and S. Shen, Biomaterials, 2017, 143, 130. 